\title{
Percutaneous placement of large cannula into the internal jugular vein for minimally invasive surgery: Where do we go?
}

\author{
William C. Oliver, Jr, MD
}

From the Department of Anesthesiology, Mayo Clinic, Rochester, Minn.

Disclosures: Author has nothing to disclose with regard to commercial support.

Received for publication Aug 17, 2016; accepted for publication Aug 19, 2016; available ahead of print Sept 28, 2016

Address for reprints: William C. Oliver, Jr, MD, Department of Anesthesiology, Mayo Clinic, 200 First St SW, Rochester, MN 55905 (E-mail: oliver.william@mayo.edu).

J Thorac Cardiovasc Surg 2016;152:1600-1

0022-5223/\$36.00

Copyright (c) 2016 by The American Association for Thoracic Surgery

http://dx.doi.org/10.1016/j.jtevs.2016.08.035

Minimally invasive cardiac surgery has increased in the last decade partly related to reduced length of hospital stay, better cosmetics, increased patient satisfaction, and comparable outcomes with traditional cardiac surgery. ${ }^{1}$ An important difference is cannulation for cardiopulmonary bypass. Because there is limited or no sternotomy, cannulas are percutaneously inserted into a femoral vein to the right atrium. An additional $15 \mathrm{~F}$ to $21 \mathrm{~F}$ cannula may be placed percutaneously via the right internal jugular vein (RIJV) at the junction of the superior vena cava (SVC) and right atrium to improve venous drainage and surgical exposure. However, the cannula is considerably larger than the multilumen $7 \mathrm{~F}$ to $9 \mathrm{~F}$ catheter inserted into the RIJV for hemodynamic monitoring and administering fluid and vasoactive medications.

Any catheter in the upper-extremity veins is at increased risk to cause catheter-related thrombosis (CRT). ${ }^{2}$ This can transition to a more serious condition referred to as "upper-extremity deep venous thrombosis" (UEDVT), which has been on the rise. ${ }^{3}$ The rates may vary depending on patient selection, study design, different diagnostic modality, catheter type, and indwelling catheter duration. $^{2,4,5}$ If symptoms of thrombosis are present, the incidence of CRT is reported as $0 \%$ to $28 \%$; however, when patients are routinely screened, the incidence is $2 \%$ to $67 \% .^{5}$ Most of these studies did not include cardiac surgical patients or catheters larger than 7.5F. Fabiani and colleagues $^{6}$ performed Doppler ultrasound (DUS) on 116 patients undergoing cardiac surgery before insertion and after removal of $8 \mathrm{~F}$ to $9.5 \mathrm{~F}$ introducer sheaths. The incidence of RIJV thrombus was $26.4 \%$ despite the average catheter duration of only $3.9 \pm 2$ days. The lack of uniformity in the definition of a thrombus is largely responsible for this degree of variability.

In this issue, $\mathrm{Oh}$ and colleagues ${ }^{7}$ are the first to report the incidence of thrombus in large cannulas placed percutaneously in the RIJV for instituting cardiopulmonary bypass. Ultrasound of the RIJV was conducted on 123 patients immediately before insertion of a $21 \mathrm{~F}$ cannula

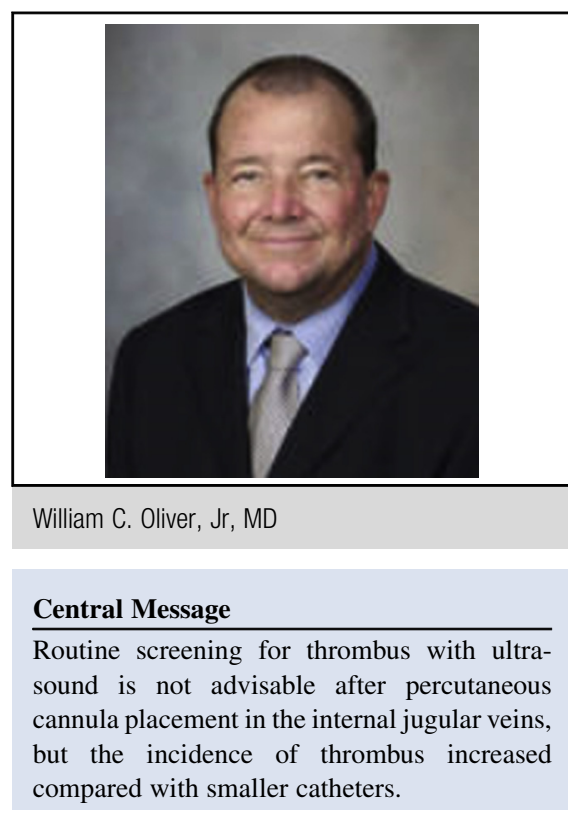

See Article page 1592 .

and at 24 and 48 hours subsequently. Sixty-eight patients $(56.2 \%)$ had a new echogenic mass present in the RIJ at 24 hours and remained at 48 hours. Surprisingly, RIJV thrombus occurred in half of these patients in a period of hours not days. The concern is that even without symptoms, thrombus may transition to UEDVT, which is associated with a risk of post-thrombotic syndrome and pulmonary embolus (PE). ${ }^{3}$ Post-thrombotic syndrome can result in permanent injury.

The only previous experience with percutaneous cannulation of the RIJV with such large cannulas is with venovenous (VV) extracorporeal membrane oxygenation (ECMO). Cannulation for VV ECMO often involves percutaneous placement of a $21 \mathrm{~F}$ to $25 \mathrm{~F}$ single-lumen cannula or $27 \mathrm{~F}$ to $31 \mathrm{~F}$ dual-lumen cannula in the RIJV. Cooper and colleagues ${ }^{8}$ evaluated 89 of 100 patients placed on VV ECMO with DUS after decannulation. ${ }^{8}$ Sixteen patients $(18.1 \%)$ had deep vein thrombosis, but a larger percentage of thrombosis occurred in the RIJV. The relative risk of thrombosis was 8 times greater with the larger dual-lumen cannula compared with the smaller cannula.

$\mathrm{Oh}$ et $\mathrm{al}^{7}$ state, "a routine ultrasonography evaluation during insertion of a percutaneous SVC catheter is recommended to identify an asymptomatic thrombosis." A factor that weakens this recommendation is their 
definition of a thrombus: “...echogenic mass was considered a thrombosis related to the percutaneous SVC catheter when it was newly detected at 24 hours." The definition of a thrombus is strongly related to the incidence of CRT in studies. ${ }^{2}$ Specific information about whether the thrombus is partially or totally occlusive is important in determining the prognosis in patients with larger catheters. ${ }^{2}$ Although the maximal cross-sectional area of the RIJV significantly decreased and the RIJV venous flow velocity significantly increased from the preoperative period to 48 hours, these changes were not clinically significant. The authors recommend routine screening because thrombus formed without symptoms. In previous studies with smaller catheters, the majority of CRTs remain subclinical, with symptomatic UEDVT occurring in only $1 \%$ to $5 \%$ of patients. ${ }^{9}$ However, there is support for DUS screening with CRT because of asymptomatic UEDVT. ${ }^{10}$ A valuable difference in the current study from other studies concerning CRT is that thrombus forms even though the large cannula is removed quickly.

Routine screening for thrombus also compels the clinician to consider anticoagulation options if a thrombus is identified. The possibility of a fatal PE leads many to support the initiation of anticoagulation if UEDVT is observed with a central venous catheter, but little data exist regarding anticoagulation and catheter-associated UEDVT. $^{11}$ Malinoski and colleagues ${ }^{2}$ prospectively screened all critically ill surgical and trauma patients within 48 hours of admission and then weekly with DUS of the upper extremities because a central venous catheter was present in most. The incidence of UEDVT was only $15 \%$. More than half of all UEDVTs resolved before discharge, and only $2 \%$ embolized. Frizzelli and colleagues ${ }^{12}$ performed DUS before insertion of a central venous catheter in 815 patients in the intensive cardiac rehabilitation unit after cardiac surgery. They found CRT in 386 patients $(48 \%)$. Patients were receiving anticoagulation, antiplatelet medications, or some combination of both. At 3 months, there were no cases of PE among patients receiving an anticoagulant, but 6 patients had nonfatal $\mathrm{PE}$ on antiplatelet therapy. The prevalence of PE in the whole series of 815 patients was only $0.7 \%$. Likewise, Major and colleagues ${ }^{13}$ looked retrospectively at screening with DUS that was performed in medical and surgical patients in the intensive care unit. The incidence of UTDVT was $33 \%$. Sixty-percent of patients received anticoagulant therapy. There was no difference in 30-day and 12-month survivals for those receiving anticoagulation. The rate of symptomatic, confirmed PE was $6 \%$ without mortality.
The findings of this study lay the foundation for future studies looking at percutaneous large cannula placement in the RIJV. The appearance of thrombus in such a brief time will need to be addressed to determine any preexisting conditions that might accelerate the occurrence of CRT with percutaneously placed cannula. Data about the progression of thrombus beyond 48 hours also will be helpful. Understanding the progression of CRT in these patients with brief cannula durations may better define the role of anticoagulation and direct it to those at greatest risk for UEDVT and complications. However, at this time, without such studies, routine screening of patients with percutaneous cannula placement is not advisable.

\section{References}

1. Suri RM, Taggarse A, Burkhart HM, Daly RC, Mauermann W, Nishimura RA, et al. Robotic mitral valve repair for simple and complex degenerative disease: midterm clinical and echocardiographic quality outcomes. Circulation. 2015 132:1961-8.

2. Malinoski DJ, Ewing T, Patel MS, Nguyen D, Le T, Cui E, et al. The natural history of upper extremity deep venous thromboses in critically ill surgical and trauma patients: what is the role of anticoagulation? J Trauma. 2011;71: 316-21.

3. Bernardi E, Pesavento R, Prandoni P. Upper extremity deep venous thrombosis Semin Thromb Hemost. 2006;32:729-36.

4. Timsit JF, Farkas JC, Boyer JM, Martin JB, Misset B, Renaud B, et al. Central vein catheter-related thrombosis in intensive care patients: incidence, risks factors, and relationship with catheter-related sepsis. Chest. 1998;114:207-13.

5. Rooden CJ, Tesselaar ME, Osanto S, Rosendaal FR, Huisman MV. Deep vein thrombosis associated with central venous catheters - a review. J Thromb Haemost. 2005;3:2409-19.

6. Fabiani A, Pittiruti M, Russo S, Sanson G. Early-onset thrombosis of internal jugular vein associated with introducer catheter for heart catheterization in cardiac surgery. $J$ Vasc Access. 2015;16:57-63.

7. Oh CS, Rhee KY, Yoon TG, Kim SH. Assessment of thrombosis in right internal jugular vein after percutaneous superior vena cava catheter insertion during cardiovascular surgery with cardiopulmonary bypass. J Thorac Cardiovasc Surg. 2016;152:1592-9.

8. Cooper E, Burns J, Retter A, Salt G, Camporota L, Meadows CI, et al. Prevalence of venous thrombosis following venovenous extracorporeal membrane oxygenation in patients with severe respiratory failure. Crit Care Med. 2015; 43:e581-4.

9. Geerts W. Central venous catheter-related thrombosis. Hematology. 2014;2014 306-11.

10. Saranteas T, Mandila C, Poularas J, Papanikolaou J, Patriankos A, Karakitsos D, et al. Transesophageal echocardiography and vascular ultrasound in the diagnosis of catheter-related persistent left superior vena cava thrombosis. Eur J Echocardiogr. 2009;10:452-5.

11. Mino JS, Gutnick JR, Monteiro R, Anzlovar N, Siperstein AE. Line-associated thrombosis as the major cause of hospital-acquired deep vein thromboses: an analysis from National Surgical Quality Improvement Program data and a call to reassess prophylaxis strategies. Am J Surg. 2014;208:45-9.

12. Frizzelli R, Tortelli O, Di Comite V, Ghirardi R, Pinzi C, Scarduelli C. Deep venous thrombosis of the neck and pulmonary embolism in patients with a central venous catheter admitted to cardiac rehabilitation after cardiac surgery: a prospective study of 815 patients. Intern Emerg Med. 2008;3: 325-30.

13. Major KM, Bulic S, Rowe VL, Patel K, Weaver FA. Internal jugular, subclavian, and axillary deep venous thrombosis and the risk of pulmonary embolism. Vascular. 2008;16:73-9. 